\title{
A Narrative Review of Smoking Cessation Practices in Jordan
}

\author{
Sami Saqf el Hait ${ }^{1 *}$ and Iman A Basheti ${ }^{2}$ \\ ${ }^{1}$ Department of CLS Quality \& Compliance, Johnson \& Johnson Consumer Saudi Arabia Limited, Saudi Arabia \\ ${ }^{2}$ Department of Clinical Pharmacy \& Therapeutics, Applied Science Private University, Jordan
}

Submission: February 17, 2017; Published: March 22, 2017

*Corresponding author: Sami Saqf el Hait, Department of CLS Quality \& Compliance, Johnson \& Johnson Consumer Saudi Arabia, Jeddah 23422, Saudi Arabia, P. O. Box 7462, Tel: +966 (012) 2722515; +966 (0) 534212444; Email: salhait@its.jnj.com

Abstract

Aim: To explore the management of smoking cessation practices based on Jordanian national clinical guidelines from a pharmacy perspective.

Methods: A search was made of international peer-reviewed literature in Pub Med, Medline, Cochrane Library and the grey literature. This document provides a review of a relevant literature including a general overview of smoking practices, therapeutic goals, pharmacological treatment, and the role of pharmaceutical care. The epidemiology of smoking practices was explored, and an overview of new approaches for treatment and management collated.

Results: The search yielded studies and information that met the inclusion criteria. Pharmacological management, tobacco dependence treatment (TDT), and the prevalence of smoking practices in Jordan were also documented.

Conclusion: Research examining the pharmacists' role in the community in counselling, inducing behaviour change, and exploring the needs of patients who suffer from tobacco dependence is of importance to optimize health outcomes and minimize costs related to treatment and complications.

Keywords: Smoking cessation; Jordan; Pharmacy; Pharmacotherapeutic; Community

Abbreviations: TDT: Tobacco Dependence Treatment; USA: United States of America; WHO: World Health Organization; ICD: International Classification of Diseases; HCP: Healthcare Providers; NRTs: Nicotine Replacement Therapy; nAChRs: Nicotinic Cholinergic Receptors; UK: United Kingdom; KHCC: King Hussein Cancer Centre; JFDA: Jordan Food and Drug Administration

\section{Introduction}

The health effects of tobacco use, including the increased risk of non-communicable diseases, have been thoroughly documented in the literature; and the public health benefits of eliminating tobacco use are irrefutable [1]. Tobacco is the second leading cause of death globally, resulting in nearly five million deaths a year [2]. Tobacco is the only legal product available to the consumers that causes the death of about 50 percent of its regular users [2]. Despite worldwide anti-smoking campaigns, cigarette smoking is growing in third-world countries [3], while a decline was recently documented in numerous developed countries, such as the United States of America (USA) [4] and Australia [5]. Studies conducted in the Middle East reported that at least $30-40 \%$ of Arab men are regular smokers [6]. This problem is continuing despite the high taxes applied by the

Arabiccountries, increasing the prices of tobacco products to almost tripleits original pricein other countries around the world [6]. Unfortunately, tobacco use rates in Jordan are currently ranked amongst the highest in the Middle East and the world [7], both among adult users as well as the youth. Smoking rates documented for Jordanian people appear to be rising especially in the 12 to 18 year age category [7]. More than half of the Jordanian population are considered regular smokers [7]. One third (30\%) of the Jordanian men aged 18 or more are smokers compared with $26 \%$ of the men from the USA [6].

Smoking has been called the chief, avoidable cause of death in Jordan [3], and is now regarded as the most important public health issue in the country [8]. In contrast, the majority of Jordanian women smoke narghile (water pipe), either solely 
(53\%) or to a lesser extent, together with cigarettes $(14 \%)$ [9]. The female preference of narghile reflects the social taboo and cultural issues against cigarette smoking by women in Jordan, which is considered among the conservative countries in the region [9]. Cardiovascular diseases and cancer have been classified as the leading causes of death in Jordan [10]. Beside tobacco consumption, Jordanians are facing additional health challenges [10], including high prevalence of poor nutrition, obesity and physical inactivity [10]. With nicotine dependence being classified as a 'disease' by the World Health Organization (WHO) International Classification of Diseases (ICD-10-CM Diagnosis Codes 2013), addressing each patient's needs individually and providing adequate treatment requires a thorough understanding of the pharmacological principles of addiction, specialised Pharmacotherapeutic and clinical knowledge, psychological and sociological skills [11].

\section{Review of the Literature}

A literature search was performed, from 2013 to 2016 in Jordan, to retrieve information on evidenced-based smoking cessation practices. Search terms used included smoking, cessation, tobacco dependence treatment, patients, needs, counselling, adults, knowledge, pharmacotherapy, guidelines, and support. The information included in this review was extracted from the Pub Med, Medline and Cochrane Library databases; and the grey literature which is produced in all levels of government, academics, business and industry in print and electronic formats, but which is not controlled by commercial publishers, including evidence based guidelines, unpublished theses, and reports [12].

\section{National Clinical Guidelines}

The Jordan Tobacco Dependence Treatment Guidelines Local Group developed a local tobacco dependence treatment (TDT) guidelines for health care professionals in the country and the region [13]. This guideline aims to cover multiple objectives which include the following:

i. to assemble all information related to TDT that is relevant to Jordan in a single resource for healthcare providers (HCP);

ii. to review international research and guidelines on TDT and create a broad, uniform, evidence-based local guideline;

iii. to support ongoing educational activities for HCP on the local level;

iv. to reinforce the message that systematic means of TDT is required for implementation within the different healthcare settings;

v. to provide an official guideline to assist HCP responding to the call for integration of TDT clinical services into their practice settings; and vi. To reaffirm the Jordanian ministry of health commitment to the world health organization's framework convention on tobacco control [13].

TDT interventions in the Jordanian guideline include several strategies:

i. brief advice,

ii. face to face support, and pharmacotherapy for tobacco dependence.

\section{Brief advice}

Brief advice provided by clinical practitioners leads to an increment in the overall tobacco abstinence rates [10]. Healthcare providers' delivered brief interventions enhance smokers' motivation and increase the likelihood of future quit attempts [10]. This is also true even in the case where the smoker is not willing to make a quit attempt [10]. Brief advice is intended to help patients realize the risks they are exposed to as a result of their tobacco use, and the benefits they will gain once they quit [10]. Quitting smoking can provide immediate and long-term health benefits (Table 1) $[10,14]$. These immediate benefits include reductions in heart rate and blood pressure in addition to patients noticing a decrease in phlegm and improved breathing within one month period $[10,14]$. Long term benefits include a reduction in smoking related mortality of more than $90 \%$ if patients quit smoking before 30 years of age, and by $50 \%$ when patients quit before age 50 [10,14].

Table 1: Health Risk Reductions with smoking cessation.

\begin{tabular}{|c|}
\hline Health Risk Reductions with smoking cessation \\
\hline - Cancer, particularly lung cancer \\
- Cardiovascular disease including stroke, myocardial infarction, \\
coronary heart disease, and peripheral vascular disease \\
- Respiratory diseases including emphysema, chronic obstructive \\
pulmonary disease, coughing, wheezing and shortness of breath \\
- The rate of decline in lung function \\
- Infertility rates in young women in the reproductive age, and the \\
risk of delivering a baby of low birth weight
\end{tabular}

\section{Face-to-Face support}

HCPs can provide face-to-face educational support for smokers who are interested in smoking cessation [15]. This involves assisting the smoker in quitting by providing counselling and advice, prescribing appropriate medications, and following-up with the patient with regards to therapeutic outcomes and goal setting [10]. Face-to-face support can take place in a healthcare provider-to-patient setting or a in a group educational setting $[10,16]$. Face-to-face educational and behaviouralinterventionshave been found to increase 6-12 month continuous smoking abstinence rates by $4 \%$ compared with providing written educational materials or providing brief advice [16]. The evidence indicates that smoking quit rates are generally higher when medication is used in combination with face-to-face support [17]. Thus in ideal clinical practice 
circumstances, face-to-face education and support together with medication use should be used in conjunction with one another to enhance outcomes and increase the smoking quit rates [18]. Multi-educational sessions are important to review goals set between the patient and the healthcare professional in terms of quitting date, medication adherence and socio-behavioural outcomes [18].

\section{Pharmacotherapeutic Interventions}

A. General principles of pharmacotherapy: Medications for smoking cessation have generally been shown to be safe and cost-effective [19]. When there are no contraindications, pharmacological therapy should be offered to any tobacco user who wants to quit smoking [20]. All Pharmacotherapeutic regimens should be accompanied by counselling, as these are more effective in combination than each given alone [21]. It is principally important that patients' report of withdrawal symptoms be inquired about and used to correctly adjust medication doses during treatment [21]. The start of tobacco dependence treatment presents a particularly challenging period for the smoker [10]

Thus, intensive use of medications is important to ensure they are being used to achieve their maximum effect [10]. The underuse of therapy (lower doses or single agents when combinations are more appropriate) can lead to poorer treatment outcomes and an inefficient use of medications [10]. Increasingly, evidence is suggesting that more intensive Pharmacotherapeutic interventions (particularly for highly dependent smokers) are safe and can improve cessation outcomes such as the achievement of abstinence or sustaining it [16]. Examples of intensive Pharmacotherapeutic interventions include: longer duration of therapy, higher doses of conventional agents, combination therapy with multiple agents (e.g. longacting with short-acting nicotine replacement therapy (NRTs); oral agents with long or short-acting NRTs) $[10,16]$.

B. Monotherapies: The following medication categories are used for the treatment of tobacco dependence.

\section{I.Nicotine replacement therapies (NRTs)}

There are two- types of NRTs:

i. Long-acting - nicotine patch

ii. Short-acting - nicotine lozenge and gum which are licensed in Jordan, and the inhaler, nasal spray, sublingual tablet, and mouth mist/spray which are not licensed in Jordan.

NRT medications act on nicotinic cholinergic receptors (nAChRs) to mimic or replace the effects of nicotine from tobacco use [22]. NRT is believed to facilitate smoking cessation in numerous methods [22]. The principal mechanism of action is the relief of withdrawal symptoms when a person stops tobacco use [23]. Amelioration of these symptoms is observed with relatively low blood levels of nicotine [22]. A second mechanism of the benefit of NRT is the positive reinforcement, particularly for stress-relieving effects [22]. The degree of positive reinforcement is related to the pharmacokinetics of NRTs with regards to rapidity of absorption and the concentration level of nicotine achieved in arterial blood [22].

This is most relevant with rapid-delivery formulations such as nicotine nasal spray and, to a lesser extent, nicotine gum, inhaler, and lozenge $[10,22]$. The use of these nicotine replacement medications allows smokers to dose themselves with nicotine when they have the urge to smoke cigarettes [22]. Nicotine patches, on the other hand, deliver nicotine gradually and produce sustained nicotine levels throughout the day, thus not providing much positive reinforcing effects [24]. A third possibility for the mechanism of NRT is in the benefit related to the ability of nicotine medications to desensitize nicotinic receptors [25], thus, resulting in a reduced effect of nicotine from cigarettes [25]. All NRT medications deliver lower concentrations of nicotine compared to those of cigarettes [10]. The nasal spray delivers the highest concentration and has the fastest onset of action compared to other formulations of NRTs; thus most closely mimics the effect of a cigarette [10].

\section{II.Varenicline}

Varenicline is one of the first-line TDT medication used for smoking cessation with a mechanism of action acting on the nicotinic acetylcholine receptor ( $\alpha 4 \beta 2$ receptor) partial agonist and binds to nicotinic receptors in the brain [26]. Consequently, symptoms of craving and withdrawal are alleviated because varenicline's binding prevents binding of nicotine from tobacco smoke, thus reducing the effects of tobacco. This is also because varenicline also induces dopamine release in a similar mechanism to that of nicotine. Adverse effects have raised concerns regarding the use of varenicline in clinical practice. However, such adverse effects are rare, and pharmacovigilance studies have been indecisive about the adverse events [27]. Documents adverse effects include.

i. Cardiovascular safety: studies are inconsistent with the significance of cardiovascular events compared between varenicline and non-vareniclinepatients [28]. However, research done in this area shows that the rate of cardiovascular adverse events is very low with a rate of $0.3 \%$ to $1.06 \%$ [27].

ii. Varenicline's product label contains warning about suicidal ideation and other neuropsychiatric adverse effects. Conversely, these events are rare to occur in patients with and without pre-existing psychiatric disease [29]. However, there is no definite evidence regarding varenicline use in psychiatric patients, particularly because some of these adverse events may actually be symptoms of nicotine withdrawal rather than a medication adverse effect [10]. Nevertheless, patients using vareniclineshould be observed for symptoms such as changes in behaviour, hostility, agitation, depressed mood, and suicideattempts [10], albeit there is no evidence of increased risks 
compared to placebo users [29] Varenicline was associated with and increased risk of sleep disorders, insomnia, and abnormal dreams [29]. These adverse effects are well documented in the literature and are included in the drug's patient information leaflets [29].

\section{Bupropion}

Although Bupropion is the first-line medication in smoking cessation guidelines [30] which was licensed in the USA in 1997 and in the United Kingdom (UK) in 2000 [31], it is not currently licensed in Jordan but is only available at the King Hussein Cancer Centre (KHCC)[10]. Bupropion inhibits the reuptake of nor epinephrine and dopamine and may inhibit nicotinic acetylecholinereceptor function [31], but its precise mechanism of action as a smoking cessation aid is not yet clear. Cigarette smoking results in nicotine absorption into the blood stream which as a result crosses the blood brain barrier [31]. This crossing to the blood brain barrier leads to the release of dopamine into the synaptic cleft of the dopaminergic pathways in the brain [31]. Following a reduction of nicotine intake, dopamine reuptake into the axon terminal vesicles follows [31]. In smoking cessation, bupropion is thought to exert its mechanism of action by inhibiting this dopamine reuptake into the axon terminal vesicles, most probably by its influence on the dopamine transporter system [31]. Some patients had changes in their behaviour, hostility, agitation, depression, and suicidal thoughts or actions while taking bupropion as a smoking cessation aid [10].

Bupropion's product label contains a warning box about suicidal attempts and thoughts as well as other neuropsychiatric adverse events [10]. The study by Anthenelli et al. [32], did not show a significant increase in neuropsychiatric adverse effects attributable to bupropion in contrast to nicotine patch or placebo. Yet, Bupropion users should be carefully observed for these neuropsychiatric symptoms [10,33]. A dose-related risk of seizures has been documented with bupropion use (the risk is $1: 1000$ or $0.1 \%$ at doses of up to $300 \mathrm{mg}$ daily) $[33,34]$. Therefore, prescribing bupropion should be avoided if the patient appears to have an increased risk for seizures (e.g. recovering from head trauma) [10]. Comparing effectiveness, Varenicline was found to be more effective than all of the other cohorts including the placebo, nicotine patch, and bupropion in helping smokers achieve smoking cessation, while bupropion and nicotine patch were more effective relative to placebo in helping smokers achieve abstinence [32].

\section{Other Pharmacological agents}

Nortriptyline is a tricyclic anti-depressant used as a second line medication in smoking cessation [35], although it is not approved for this indication by the FDA in the USA [36]. It causes many adverse effects including dry mouth and dizziness, blurred vision, constipation and urinary retention when used in doses of $>150 \mathrm{mg} /$ day [35]. Overdose of nortriptyline leads to severe and potentially fatal cardiovascular adverse events such as palpitation, irregular or heavy heart beats, tachycardia, orthostatic hypotension and nervous system toxicities such as dizziness, headache, concentration disorders, paraesthesia, ataxia, strange body movements, tremors, convulsions, and seizures [35]. In smoking cessation clinical trials, the typical nortriptyline dose used was 75-100 mg per day. Nortriptyline doubles the rates of smoking abstinence when compared with placebo [35].

Clonidine, as with nortryptiline, is a second-line medication in TDT [36]. Clonidine is an alpha-2-adrenergic agonist and is used as an anti-hypertensive medication where this is the only indication it is approved for by the USA FDA [37]. In smoking cessation, it is thought to counteract the CNS effects of nicotine withdrawal such as craving and anxiety [37]. Cytisinehas similar pharmacological properties to that of varenicline, and is currently licensed in some Eastern European markets, and is less costly than varenicline [10]. Thus, it is a potential agent to be licensed in the future in Jordan for TDT [10].

\section{Combination therapies}

Combination of drugs in smoking cessation therapy provides higher abstinence rates compared to placebo or NRT monotherapy. In their review, Shah et al. [38] stated that adverse effects and adherence in combination TDT therapies were similar to placebo or NRT monotherapy. Bupropion was the only monotherapy with better cessation outcomes than combination therapy [39]. Nonetheless, adverse effects limit its use [39]. Additional studies are required to establish the role of combination therapy in smoking cessation in terms of optimal therapy combinations, duration of treatment, dosing schedules and preferred agents for special populations [40].

\section{TDT for Water pipe Smokers}

In a neighbouring country to Jordan, Syria, water pipe smokers were not as interested as cigarette smokers in smoking abstinence, with only $28.4 \%$ of participants expressing interest in quitting [41]. Based on similar demographics in Jordan, where water pipe smoking is increasing among the youth and is leading to cigarette smoking [42], it is recommended to explore people's willingness to quit smoking and to participate in TDT interventions. There are currently no evidence based guidelines regarding treatment of water pipe dependence [43]. However, the Jordanian guidelines recommend the following suggestions [10]: Provide counselling and motivational interviewing (creating interest for water pipe smokers to quit); avoid comparing cigarettes to water pipe because both are bad for health with serious adverse effects upon the users; using pharmacological treatment. Although, there is insufficient evidence regarding the use of medicines which are approved for cessation from cigarette smoking in water pipe patients, HCPs with sufficient expertise in cigarette smoking cessation practices may choose to use them at their own discretion. 


\section{Other aspects of management}

a. Misconceptions about the use of NRTs: General misconceptions about the use of NRTs have prevented their use in healthcare practices and need to be noted to improve patient knowledge and clinical outcomes [44]. These include:

i. Inaccurate perception of the adverse effects of NRTs and any harmful effects that are associated with nicotine delivered by NRTs are much lower than the risks associated with smoking.

ii. Concerns regarding abuse with and dependence on NRTs are exaggerated. Using lower doses of NRTs, by patients, than recommended in the guidelines and prescription information, may reduce the chances of successful treatment outcomes. This is particularly important at the start of treatment when withdrawal symptoms are most severe.

iii. NRTs can be safely used in patients with cardiovascular disease with the exception of those who are hemodynamically unstable, e.g. those patients who have suffered from a recent heart attack.

b. Smoking cessation interventions in Jordan: The Jordan Ministry of Health has three smoking cessation clinics at Primary Health Care centres across three regions of the kingdom (south, middle and north) [10]. These clinics offer counselling and pharmacotherapy free of charge to smokers who have the desire to quit. These are the only available public health care sites for treatment in Jordan [16]. At KHCC, there is another smoking cessation clinic that provides counselling and pharmacotherapy to cancer patients mainly, as well as smokers from the general population.

The TDT medications registered and available in Jordan include Nicotine Replacement Therapies (NRTs), specifically patches, gums and lozenges; and varenicline. Even though Bupropion is not registered at the Jordan Food and Drug Administration (JFDA), it is available at KHCC. Over the recent years, TDT training in Jordan has increased. Thus far, since 2011, about 200 HCPs, including physicians, dentists, pharmacists, and nurses, were trained on TDT use, and an additional 327 health educators (school counsellors and teachers) were trained in tobacco control and TDT basic principles. Based on the available evidence from various countries such as Spain [45], Australia [46], USA [47] and the UK [48], it is recommended that HCPs' involvement in smoking cessation clinical interventions be based on the following criteria: access to smokers in the primary and secondary care settings, appropriate training based on evidence based guidelines, and healthcare provider's interest and experience in TDT.

c. Role of the pharmacist in smoke cessation: Pharmacists can deliver regular TDT interventions to a large number of smoking people in the community setting [45].
Community pharmacists, consequently, have an excellent opportunity in health promotion and in TDT interventions as part of their clinical services provided to patients [45]. Pharmacists' role as a provider of TDT, available without prescription in Jordan, similarly to those in Spain [45] and other developed countries [11,46-48] means that they are ideally placed to support patients who want help to quit smoking. Pharmacists role should go further than giving advice on the correct use of medicine to providing evidence based clinical services aimed at helping patients achieve abstinence and, when needed, referring patients to the relevant HCP [49]. Pharmacists can identify smokers and ensure that they have access to all available kinds of support programs in the country.

Pharmaceutical care has a number of specific characteristics that enable pharmacists, as HCPs to play an active role in smoking cessation interventions [45]. Studies performed to date indicate that interventions provided by trained community pharmacists can have a positive effect on smoking cessation abstinence rates [45]. In Jordan, previous research by Al Zoubi et al. [50], showed that pharmacists when compared to physicians have significantly more frequent practice of most steps of treating tobacco use and dependence clinical practice guidelines. However, there has been no study to measure the knowledge of community pharmacists in this area, and actual effect of delivering smoke cessation pharmaceutical care services on clinical and quality of life outcomes based on the Jordanian relevant guidelines.

\section{Conclusion}

This review of the literature has highlighted smoking practices and the importance of smoke cessation as a global health issue in general, and in Jordan specifically. It also discussed therapeutic goals, pharmacological treatment, and the impact of treatment on quality of life. Future studies should examine adherence of community pharmacists to evidence based medicine at the pharmacological and lifestyle levels. Assessment of patients' knowledge about smoking health risks and abstinence benefits and the effect of pharmaceutical care on engaging smokers in self-management education to facilitate behaviour change, adopt smoke cessation strategies, achieve better clinical and quality of life outcomes and minimize costs related to smoke complications.

\section{References}

1. Schane RE, Ling PM, Glantz SA (2010) Health Effects of Light and Intermittent Smoking: A Review. Circulation 121(13): 1518-1522.

2. Proctor RN (2013) Why ban the sale of cigarettes? The case for abolition. Tob Control 22(1): i27-i30.

3. Warren CW, Jones NR, Peruga A, Chauvin J, Baptiste JP, et al. (2008) Global youth tobacco surveillance, 2000-2007. MMWR Surveill Summ 57(1): 1-21.

4. Paoletti L, Jardin B, Carpenter M, Cummings KM, Silvestri GA (2012) Current Status of Tobacco Policy and Control. J thorac imaging 27(4): 213-219. 
5. Dessaix A, Maag A, McKenzie J, Currow D (2016) Factors influencing reductions in smoking among Australian adolescents. Public Health Res Pract 26(1): e2611605.

6. Al-Matubsi HA, Kanaan RA, Hamdan F, Salim M, Oriquat GA, et al. (2011) Smoking Practices in Jordanian People and their Impact on Semen Quality and Hormonal Levels Among Adult Men. Cent Eur J Public Health 19(1): 54-59.

7. Haddad LG, Malak MZ (2002) Smoking habits and attitudes towards smoking among university students in Jordan. Int J Nurs Stud 39(8): 793-802.

8. Alzyoud S, Kheirallah KA, Weglicki LS, Ward KD, Al-Khawaldeh A, et al. (2014) Tobacco Smoking Status and Perception of Health among a Sample of Jordanian Students. International Journal of Environmental Research and Public Health 11(7): 7022-7035.

9. Dar-Odeh NS, Bakri FG, Al-Omiri MK, Al-Mashni HM, Eimar HA, et al (2010) Narghile (water pipe) smoking among university students in Jordan: prevalence, pattern and beliefs. Harm Reduction Journal 7(1): 1-6.

10. Hawari F, Ayub H, Obeidat N, Habashneh M (2014) Jordan Guidelines for Tobacco Dependence Treatment "Helping Smokers Quit" Jordan: King Hussein Cancer Foundation and King Hussein Cancer Center. Jordan.

11. Saba M, Bittoun R, Kritikos V, Saini B (2013) Smoking cessation in community pharmacy practice-a clinical information needs analysis. Springer Plus 2: 449.

12. Saleh AA, Ratajeski MA, Bertolet M (2014) Grey Literature Searching for Health Sciences Systematic Reviews: A Prospective Study of Time Spent and Resources Utilized. Evidence based library and information practice $9(3): 28-50$.

13. Ayub H, Obeidat N, Leischow S, Glynn T, Hawari F (2015) Jordan tobacco dependence treatment guidelines: rationale and development. Eastern Mediterranean Health Journal 21(11): 844-850.

14. Pirie K, Peto R, Reeves GK, Green J, Beral V, et al. (2013) The 21st century hazards of smoking and benefits of stopping: a prospective study of one million women in the UK. Lancet 381(9861): 133-141.

15. Borland R, Li L, Driezen P, Wilson N, Hammond D, et al. (2012) Cessation assistance reported by smokers in 15 countries participating in the International Tobacco Control (ITC) policy evaluation surveys. Addiction 107(1): 197-205.

16. West R, Raw M, McNeill A, Stead L, Aveyard P, et al. (2015) Health-care interventions to promote and assist tobacco cessation: a review of efficacy, effectiveness and affordability for use in national guideline development. Addiction 110(9):1388-1403.

17. Lancaster T, Stead LF (2005) Individual behavioural counselling for smoking cessation. Cochrane Database of Systematic Reviews 18(2): CD001292.

18. Stead LF, Lancaster T (2005) Group behaviour therapy programmes for smoking cessation. Cochrane Database of Systematic Reviews 18(2): CD001007.

19. Anczak JD, Nogler RA (2003) Tobacco Cessation in Primary Care: Maximizing Intervention Strategies. Clinical Medicine and Research 1(3): 201-216.

20. Galanti LM (2008) Tobacco smoking cessation management: integrating varenicline in current practice. Vascular Health and Risk Management 4(4): 837-845.

21. Siu AL (2015) Behavioral and Pharmacotherapy Interventions for Tobacco Smoking Cessation in Adults, Including Pregnant Women: U.S.
Preventive Services Task Force Recommendation Statement. Annals of Internal Medicine 163(8): 622-634.

22. Benowitz NL (2009) Pharmacology of Nicotine: Addiction, SmokingInduced Disease, and Therapeutics. Annual review of pharmacology and toxicology 49: 57-71.

23. Cummings KM, Hyland A (2005) Impact of Nicotine Replacement Therapy On Smoking Behaviour. Annual Review of Public Health 26(1): 583-599.

24. Benowitz NL (2008) Clinical Pharmacology of Nicotine: Implications for Understanding, Preventing, and Treating Tobacco Addiction. Clinical Pharmacology \& Therapeutics 83(4): 531-541.

25. Jiloha RC (2010) Biological basis of tobacco addiction: Implications for smoking-cessation treatment. Indian Journal of Psychiatry 52(4): 301-307.

26. Singh J, Budhiraja S (2008) Partial nicotinic acetylcholine ( $\alpha 4 \beta 2)$ agonists as promising new medications for smoking cessation. Indian Journal of Pharmacology 40(5): 191-196.

27. Singh S, Loke YK, Spangler JG, Furberg CD (2011) Risk of serious adverse cardiovascular events associated with varenicline: a systematic review and meta-analysis. CMAJ 183(12): 1359-1366.

28. Chelladurai Y, Singh S (2014) Varenicline and cardiovascular adverse events: a perspective review. Therapeutic Advances in Drug Safety 5(4):167-172.

29. Thomas KH, Martin RM, Knipe DW, Higgins JPT, Gunnell D (2015) Risk of neuropsychiatric adverse events associated with varenicline: systematic review and meta-analysis. The BMJ.

30. Jiloha RC (2014) Pharmacotherapy of smoking cessation. Indian Journal of Psychiatry 56(1): 87-95.

31. Wilkes S (2008) The use of bupropion SR in cigarette smoking cessation. International Journal of Chronic Obstructive Pulmonary Disease 3(1): 45-53

32. Anthenelli RM, Benowitz NL, West R, St Aubin L, McRae T, Lawrence D, et al. (2016) Neuropsychiatric safety and efficacy of varenicline, bupropion, and nicotine patch in smokers with and without psychiatric disorders (EAGLES): a double-blind, randomised, placebo-controlled clinical trial. The Lancet 387(10037): 2507-2520.

33. Soyka M (2004) Neuropsychiatric adverse events of bupropion treatment: a brief update. International Journal of Psychiatry in Clinical Practice 8(4): 251-254.

34. Starr P, Klein-Schwartz W, Spiller H, Kern P, Ekleberry SE, Kunkel S (2009) Incidence and onset of delayed seizures after overdoses of extended-release bupropion. The American Journal of Emergency Medicine 27(8): 911-915.

35. Hughes JR, Stead LF, Lancaster T (2005) Nortriptyline for Smoking Cessation: A Review. Nicotine Tobacco Research 7(4): 491-499.

36. Herman AI, Sofuoglu M (2010) Comparison of Available Treatments for Tobacco Addiction. Current psychiatry reports 12(5): 433-440.

37. Casella G, Caponnetto P, Polosa R (2010) Therapeutic advances in the treatment of nicotine addiction: present and future. Therapeutic Advances in Chronic Disease 1(3): 95-106.

38. Shah SD, Wilken LA, Winkler SR, Lin S-J (2003) Systematic review and meta-analysis of combination therapy for smoking cessation. Journal of the American Pharmacists Association 48(5): 659-664.

39. McDonough M (2015) Update on medicines for smoking cessation. Australian Prescriber 38(4):106-111. 
40. Hurt RD, Ebbert JO, Hays JT, McFadden DD (2009) Treating Tobacco Dependence in a Medical Setting. CA: a cancer journal for clinicians 59(5): 314-326.

41. Ward KD, Hammal F, VanderWeg MW, Eissenberg T, Asfar T, et al. (2005) Are Water pipe Users Interested in Quitting? Nicotine \& Tobacco Research 7(1):149-156.

42. Jaber R, Madhivanan P, Veledar E, Khader Y, Mzayek F, et al. (2015) Water pipe a gateway to cigarette smoking initiation among adolescents in Irbid, Jordan: a longitudinal study. The international journal of tuberculosis and lung disease 19(4): 481-487.

43. Maziak W, Ward KD, Eissenberg T (2007) Interventions for waterpipe smoking cessation. Cochrane Database of Systematic Reviews 17(4): CD005549.

44. Myers MG, Strong DR, Linkec SE, Hofstetter CR, Al-Delaimy WK (2015) Predicting use of assistance when quitting: A longitudinal study of the role of quitting beliefs. Drug and alcohol dependence 149: 220-224.

45. Marín Armero A, Calleja Hernandez MA, Perez-Vicente S, MartinezMartinez F (2015) Pharmaceutical care in smoking cessation. Patient preference and adherence 9: 209-215.
46. Saba M, Diep J, Bittoun R, Saini B (2014) Provision of smoking cessation services in Australian community pharmacies: a simulated patient study. International Journal of Clinical Pharmacy 36(3): 604-614.

47. Philbrick AM, Newkirk EN, Farris KB, McDanel DL, Horner KE (2009) Effect of a pharmacist managed smoking cessation clinic on quit rates. Pharmacy Practice 7(3): 150-156.

48. Brown TJ, Todd A, O’Malley C, Moore HJ, Husband AK, Bambra C, et al. (2016) Community pharmacy-delivered interventions for public health priorities: a systematic review of interventions for alcohol reduction, smoking cessation and weight management, including meta-analysis for smoking cessation. BMJ Open 6(2): e009828.

49. Goniewicz ML, Lingas EO, Czogala J, Koszowski B, Zielinska-Danch W, et al. (2010) The Role of Pharmacists in Smoking Cessation in Poland. Evaluation the health professions 33(1): 81-95.

50. Alzoubi KH, Azab M, Khabour OF, Al-shamaila AW, Ayoub NM, et al. (2010) Smoking-cessation practice guidelines: awareness and implementation among medical teams. International Journal of Pharmacy Practice 18(2): 93-99.

Your next submission with Juniper Publishers will reach you the below assets

- Quality Editorial service

- Swift Peer Review

- Reprints availability

- E-prints Service

- Manuscript Podcast for convenient understanding

- Global attainment for your research

- Manuscript accessibility in different formats ( Pdf, E-pub, Full Text, Audio)

- Unceasing customer service

Track the below URL for one-step submission https://juniperpublishers.com/online-submission.php 